\title{
Growth hormone treatment for adults with Prader-Willi syndrome: another point of view
}

Harry J. Hirsch ${ }^{1 *}$ (D) and Varda Gross-Tsur ${ }^{1,2}$

\begin{abstract}
Growth hormone treatment for children with Prader Willi syndrome (PWS) has shown proven benefits not only in increasing final height but also with positive effects on body composition and motor development. In a recent letter to the editor, Hoybye and colleagues recommend growth hormone treatment for adults with PWS based exclusively on the genetic diagnosis and without regard for growth hormone secretory status. We question whether the benefits of growth hormone treatment in PWS adults, mainly improvement in body composition, are significant enough to justify the as yet unkown consequences of long-term treatment in an adult population. Morbidity and mortality in PWS are mainly due to complications of obesity, and growth hormone treatment does not result in a decrease in BMI or waist circumference. Increases in insulin-like factor-1 as a result of growth hormone treatment over the course of several decades in PWS adults raises concern over possible increase risk of cancer. Compliance with daily injections is likely to be poor. We suggest that efforts to provide appropriate dietary and exercise regimens may be more beneficial and cost-effective than advocating for growth hormone treatment for adults with PWS.
\end{abstract}

Keywords: Prader-Willi syndrome, Growth hormone, Obesity, Insulin-like growth factor-1

Growth hormone treatment for adults with PWS has been shown to improve body composition, increase muscle strength and endurance, and result in modest improvements in cognition as summarized in the letter to the editor by Hoybe, Holland, and Driscoll [1]. The authors recommend growth hormone treatment for all adults with a genetically confirmed diagnosis of PWS, irrespective of their responses to standard growth hormone stimulation tests or whether they had previously received growth hormone during childhood. Despite some proven benefits of growth hormone treatment, we question, for several reasons, the recommendation to advocate for growth hormone treatment of all PWS adults.

\footnotetext{
*Correspondence: hirschmd@gmail.comdriscdj@peds.ufl.edu

${ }^{1}$ Israel Multidisciplinary Prader-Willi Syndrome Clinic, Neuropediatric Unit, Department of Pediatrics, Shaare Zedek Medical Center, Jerusalem, Israel

Full list of author information is available at the end of the article
}

Improvements in body composition associated with GH (growth hormone) treatment, mainly a decrease in visceral adipose tissue (VAT) and increase in lean body mass, may not necessarily result in significant improvements in health or quality of life. PWS individuals are protected to some degree from the adverse metabolic effects of VAT. Fatty liver is rare in PWS and PWS individuals have less insulin resistance compared to individuals with non-syndromic obesity [2-5]. Nutritional intervention even without growth hormone treatment has been shown to maintain VAT within the normal reference range [6]. Morbidity and mortality in PWS result primarily from obesity-related complications and hyperphagia, such as respiratory abnormalities, choking, aspiration, gastric or intestinal perforations or obstructions and as Hoybe and colleagues stated, GH treatment does not result in decreases in BMI (body mass index) or waist circumference $[1,7]$. 
While GH treatment for adults with severe GH deficiency (mostly due to organic causes such as CNS tumors or congenital hypopituitarism) has been shown to improve quality of life, most PWS adults do not have severe GH deficiency. GH deficiency in PWS adults appears to be variably mild or partial [8-10]. We are not aware that there is any evidence for long-term benefit of GH treatment for adults who have only mild or partial GH deficiency.

Hypogonadism is a common feature of PWS and contributes to the abnormal body composition in this syndrome [11, 12]. Androgen replacement improves lean body mass, is less expensive and is more likely to be adhered to than GH injections [13].

Poor compliance with daily growth hormone injections is common in children [14]. For PWS adults, compliance is likely to be poor-at least until, as the authors point out, once-weekly GH preparations become available. Furthermore, GH treatment is expensive and recommending growth hormone for all PWS adults might sidetrack limited resources (family finances and government funding) from more basic effective aspects of PWS management such as nutritional management, exercise programs, and opening hostels designated specifically for PWS adults [15]. Pellikan et al. reported that even within the framework of a major multidisciplinary PWS clinic, $22 \%$ of the adults exercised too little and $37 \%$ were not being seen by a dietitian [12]. Addressing these more basic issues may have a greater impact on health and quality of life than might be achieved by GH treatment.

Widespread use of GH could result in inappropriate use of growth hormone in individuals with severe obesity for whom GH treatment may significantly increase obstructive sleep apnea and/or hyperglycemia. Although growth hormone treatment for children and adolescents has a proven safety record, there may be some concerns about long-term treatment of older adults with PWS. Of particular concern is the effect of "normalizing" the relatively low serum insulin-like growth factor-1 (IGF1) levels usually seen in PWS individuals. Patients with low IGF-1 levels due to congenital growth hormone deficiency or growth hormone insensitivity (e.g. Laron-type dwarfism) have significantly lower incidences of cancer, while individuals with acromegaly and higher than average levels of insulin-like growth factor-1 (IGF1) have an increased risk of cancer [16, 17]. The incidence of colorectal cancer is significantly greater for individuals with IGF-1 levels in the upper range of normal compared to those with levels in the lower range [18]. Similar population studies have shown associations with IGF-1 levels for prostate, breast, and lung cancer [19]. IGF-1 levels are usually low in most PWS individuals [20]. Even a modest increase in IGF-1 due to GH treatment might lead to an increase risk of cancer in this population.

In a recent review of published studies of growth hormone treatment in adults with PWS, treatment duration was only one to two years in most reports, while only two described treatment durations of up to five years [21]. We are not aware of any studies which describe long-term benefits or possible adverse effects during several decades of treatment in PWS adults.

GH treatment for infants and children with PWS has shown clear beneficial effects on growth, development, and body composition and has a reassuring safety record over a typical duration of 10 to 15 years of daily administration. Some PWS adults, especially those individuals who are already receiving optimal dietary management and exercise programs, may also experience some benefit from GH treatment. Nevertheless, we suggest that further long-term studies of efficacy and safety are needed before recommending life-long $\mathrm{GH}$ treatment as the standard of care for all PWS adults.

\section{Response to Harry Hirsch and Varda Gross-Tsur: Growth hormone treatment for adults with Prader-Willi syndrome: another point of view}

\section{Charlotte Höbye ${ }^{3}$, Anthony J. Holland ${ }^{4}$ and Daniel J. Driscoll $5^{5^{*}}$ on behalf of The Clinical, Scientific Advisory Board of The International Prader-Willi Syndrome Organisation}

*Correspondence: hirschmd@gmail.comdriscdj@peds.ufl.edu ${ }^{3}$ Department of Endocrinology, Karolinska University Hospital and Department of MolecularMedicine and Surgery, Karolinska Institute, Stockholm, Sweden

${ }^{4}$ Department of Psychiatry, University of Cambridge, Cambridge, UK ${ }^{5}$ Division of Pediatric Genetics and Metabolism, Department of Pediatrics, The John T. \& Winifred M. Hayward Professor of Genetics Research, Chair, Prader-Willi Syndrome Association (USA) Clinical Advisory Board, Chair, International Prader-Willi Syndrome Organization Clinical \& Scientific Advisory Board, University of Florida College of Medicine, Box 100296, Gainesville, FL 32610-0296, USA

In the letter by Dr. Hirsch and Dr. Gross-Tsur our advocacy for a general approval of growth hormone (GH) treatment of all adults with Prader-Willi syndrome (PWS) is questioned [22]. Their main arguments against our recommendation are that $\mathrm{GH}$ treatment has only been proven to have modest benefits and that the longterm effects and safety of GH treatment in adults with PWS are unknown.

Dr. Hirsch and Dr. Gross-Tsur argue that improvements in body composition associated with GH treatment are mainly due to a decrease in visceral adipose tissue (VAT) and an increase in lean body mass, which may not result in significant improvements in health or quality of life. They go on to argue that fatty liver is rare in PWS and 
insulin resistance is not pronounced, which to some degree protects people with PWS from the adverse metabolic effects of VAT, also referring to one study where intense nutritional intervention even without GH treatment was shown to maintain VAT within the normal reference range. Another argument they put forward is that morbidity and mortality are primarily caused by obesityrelated complications secondary to hyperphagia and $\mathrm{GH}$ treatment does not result in decrease in BMI (body mass index) or waist circumference. In addition, Dr. Hirsch and Dr. Gross-Tsur point out that GH deficiency in PWS adults appears to be mild or partial and evidence for long-term benefit of GH treatment for adults who have only mild or partial GH deficiency is lacking.

As stated in our letter "Time for a general approval of growth hormone treatment in adults with Prader-Willi syndrome", the hypothalamic dysfunction in PWS is permanent by nature, and therefore affected adults are expected to have the same hormone deficiencies as seen in the children [23]. GH deficiency has been for a long time accepted as part of the phenotype PWS, but a multitude of confounding factors are present and in PWS a different interpretation of the results from GH stimulation tests to those considered relevant in the typical population with GH deficiency is necessary. Therefore, it is not meaningful to grade GH deficiency in PWS or state that it is severe, mild, or partial.

Several studies of children with PWS have all shown improvements in height, body composition, cognitive function, and socialization [24, 25]. The number of studies in adults with PWS are less, but they have consistently shown improvements in body composition, physical performance, and psycho-social function [24-26]. The reduction in body fat and the increase in lean body mass are comparable to the effects of GH treatment in adults without PWS who fulfill criteria for profound GH deficiency [27]. GH's lipolytic effect is most pronounced in VAT, but studies of adults with PWS have also shown a decrease in subcutaneous fat tissue [28]. We strongly agree that $\mathrm{GH}$ is not a weight reducing drug and moreover it does not affect hyperphagia [24, 25]. GH, or androgen treatment for that matter, does not replace a strictly controlled diet or regular physical exercise. Importantly, a strict diet and physical exercise can potentiate the effects of GH on body composition, metabolic factors, and general well-being.

The use of GH treatment in grossly obese patients is not recommended in any guideline. However, this is primarily not because of the risk of side effects, but because of lack of effect. We do not agree with the concerns about a potential increase in sleep apnea and hyperglycemia with $\mathrm{GH}$ treatment. One of us $(\mathrm{CH})$ has recently published a study on GH treatment over three years in adults with PWS and an increase in sleep apnea was not seen [29]. In addition, previous studies have not shown an increase in the number of people with PWS with diabetes during $\mathrm{GH}$ treatment $[25,26]$. In contrast, the development of diabetes has been found to be related to heredity and weight increase, independent of GH treatment [30]. GH is not widely used in adults with PWS whereas a strict diet and regular physical training are baseline treatments for all adults with PWS. It is well-known that people with PWS have problems complying to both diet and to physical training, and we do not disagree that it is of utmost importance to improve the implementation of these. Despite the fact that all are on a strict diet and regular physical activity obesity remains a large problem.

We have a long experience of treatment with $\mathrm{GH}$ in PWS and compliance with the GH injections is not a big issue. However, due to the behavioral problems in PWS the daily injections can be a burden for caregivers, and we hope the weekly injections will be an improvement. Some of us have treated adults with PWS for more than three decades and we have not observed an increase in diabetes or cancer related to $\mathrm{GH}$ treatment. Indeed, PWS is a rare disease and we acknowledge that the longterm consequences of $\mathrm{GH}$ treatment are not completely known, as is also the case with GH treatment of adults with GH deficiency of other etiologies, which is a considerably larger but still a rare group of patients [31]. The available data suggests that long-term GH treatment does not increase the risk of developing diabetes or malignancies [31]. We do not know of any appropriate group of patients for comparison with adults with PWS, but find the comparison with Laron dwarfs only theoretically relevant. Likewise, patients with acromegaly have longterm GH and insulin-like growth factor-1 (IGF1) levels far above the levels obtained with GH treatment and it has not been consistently proven that the risk of cancer is increased in people with acromegaly [31]. In our view it is not appropriate to generalize from the results from the general population with a different risk factor profile for cancer to people with PWS. An improvement in quality of life with GH treatment in adults with PWS has been shown, but as anybody working with people with PWS knows, adequate and validated measures for quality of life in PWS do not exist.

If the studies on GH treatment in PWS are few it should be noted that there is only one study on testosterone treatment in adults with PWS [32]. This study showed that low dose testosterone improved body composition without significant impairments in behavior [32]. However, the long-term potential negative effects of androgen treatment in men with PWS are also unknown. Despite this Dr. Hirsch and Dr. Gross-Tsur advocate for treatment of hypogonadism as androgens replacement 
improves lean body mass, is less expensive and the argue that adherence is likely to be better than to daily $\mathrm{GH}$ injections. Further, there are no studies of treatment with sex-steroids in women with PWS and the question is how Dr. Hirsch and Dr. Gross-Tsur think they should be treated.

The costs for GH treatment are high, but adults with PWS do not need high doses of GH and a common dose to adults above 30 years of age is $0.2-0.4 \mathrm{mg}$ per day. In a rare disease, such as PWS, these costs would probably not reach the costs for multidisciplinary care and we would argue that its use together with good care brings additional benefits.

In summary, we do not agree with Dr. Hirsch and Dr. Gross-Tsur conclusions and still advocate for a general approval of growth hormone treatment in adults with Prader-Willi syndrome. We also still argue that GH treatment, with its many beneficial effects and few side effects, is a treatment that relieves some of the adverse effects of PWS in adults. Moreover, treatment with GH will improve the follow-up of adults with PWS as it has been shown for children with PWS. Whilst we are advocating for general approval of GH in adults with PWS, whether or not a person with PWS chooses to continue GH in adult life is for him/her to decide with guidance from those who support them. For some they may feel that the burden of the injections is too much, for others, they may be willing to accept this given the benefits that they have experienced. By ensuring that the principle of GH use in adults with PWS is established we make this choice possible as it is for those people with GH deficiencies for other reasons.

\section{Abbreviations}

PWS: Prader-Willi syndrome; GH: Growth hormone; VAT: Visceral adipose tissue; BMI: Body mass index = weight in kilograms/(height in meters) ${ }^{2}$; IGF-1: Insulinlike growth factor-1.

\section{Acknowledgements}

Not applicable.

\section{Authors' contributions}

Both authors participated in writing and reviewing the manuscript. Both authors read and approved the final manuscript.

\section{Funding}

We did not receive any financial support in preparing this submission.

\section{Availability of data and materials}

Data sharing is not applicable to this article as no datasets were generated or analysed during the current study.

\section{Declarations}

\section{Ethical approval}

This letter explaining our position is not an original research report and did not involve participation of patients or volunteers and therefore the declaration regarding ethics approval or informed consent is not applicable.

\section{Consent for publication}

The manuscript does not contain any individual person's data and therefore a consent statement is not applicable.

\section{Competing interests}

The authors declare that we have no competing interests.

\section{Author details}

${ }^{1}$ Israel Multidisciplinary Prader-Willi Syndrome Clinic, Neuropediatric Unit, Department of Pediatrics, Shaare Zedek Medical Center, Jerusalem, Israel. ${ }^{2}$ The Faculty of Medicine, The Hebrew University School of Medicine, Jerusalem, Israel. ${ }^{3}$ Department of Endocrinology, Karolinska University Hospital and Department of MolecularMedicine and Surgery, Karolinska Institute, Stockholm, Sweden. 'Department of Psychiatry, University of Cambridge, Cambridge, UK. ${ }^{5}$ Division of Pediatric Genetics and Metabolism, Department of Pediatrics, The John T. \& Winifred M. Hayward Professor of Genetics Research, Chair, Prader-Willi Syndrome Association (USA) Clinical Advisory Board, Chair, International Prader-Willi Syndrome Organization Clinical \& Scientific Advisory Board, University of Florida College of Medicine, Box 100296, Gainesville, FL 32610-0296, USA.

Received: 23 March 2021 Accepted: 11 July 2021

Published online: 03 August 2021

\section{References}

1. Höybye C, Holland AJ, Driscoll DJ. Clinical and Scientific Advisory Board of The International Prader-Willi Syndrome Organisation Time for a general approval of growth hormone treatment in adults with Prader-Willi syndrome. Orphanet J Rare Dis. 2021;16(1):69. https://doi.org/10.1186/ s13023-020-01651-x.

2. Fintini D, Inzaghi E, Colajacomo M, Bocchini S, Grugni G, Brufani C, Cappa M, Nobili V, Cianfarani S, Crinò A. Non-alcoholic fatty liver disease (NAFLD) in children and adolescents with Prader-Willi Syndrome (PWS). Pediatr Obes. 2016;11(3):235-8. https://doi.org/10.1111/ijpo.12052.

3. Bedogni G, Grugni G, Nobili V, Agosti F, Saezza A, Sartorio A. Is nonalcoholic fatty liver disease less frequent among women with Prader-Willi syndrome? Obes Facts. 2014;7(1):71-6. https://doi.org/10.1159/00035 8570.

4. Hirsch HJ, Gross I, Pollak Y, Eldar-Geva T, Gross-Tsur V. Irisin and the metabolic phenotype of adults with Prader-Willi Syndrome. PLoS ONE. 2015;10(9): e0136864. https://doi.org/10.1371/journal.pone.0136864.

5. Faienza MF, Brunetti G, Grugni G, Fintini D, Convertino A, Pignataro P, et al. The genetic background and vitamin D supplementation can affect irisin levels in Prader-Willi syndrome. J Endocrinol Invest. 2021. https://doi.org/ 10.1007/s40618-021-01533-4.

6. Koizumi M, Ida S, Shoji Y, Nishimoto Y, Etani Y, Kawai M. Visceral adipose tissue resides within the reference range in children with Prader-Willi syndrome receiving nutritional intervention on a regular basis. Endocr J. 2020;67(10):1029-37. https://doi.org/10.1507/endocrj.EJ19-0489.

7. Butler MG, Manzardo AM, Heinemann J, Loker C, Loker J. Causes of death in Prader-Willi syndrome: Prader-Willi Syndrome Association (USA) 40-year mortality survey. Genet Med. 2017;19(6):635-42. https://doi.org/ 10.1038/gim.2016.178.

8. Grugni G, Marzullo P, Delvecchio M, lughetti L, Licenziati MR, Osimani S, et al. Genetic Obesity Study Group of the Italian Society of Pediatric Endocrinology and Diabetology (ISPED). Stimulated GH levels during the transition phase in Prader-Willi syndrome. J Endocrinol Invest. 2020; https://doi.org/10.1007/s40618-020-01450-y.

9. Casamitjana L, Giménez-Palop O, Corripio R, Pareja R, Berlanga E, Rigla $\mathrm{M}$, et al. Glucagon stimulation test to assess growth hormone status in Prader-Willi syndrome. J Endocrinol Invest. 2021;44(3):621-9. https://doi. org/10.1007/s40618-020-01367-6.

10. Donze SH, Damen L, van Alfen-van der Velden JAEM, Bocca G, Finken MJJ, Hoorweg-Nijman GJG, et al. Prevalence of growth hormone (GH) deficiency in previously GH-treated young adults with Prader-Willi syndrome. Clin Endocrinol (Oxf). 2019;91(1):118-123. https://doi.org/10.1111/cen. 13988.

11. Hirsch HJ, Eldar-Geva T, Bennaroch F, Pollak Y, Gross-Tsur V. Sexual dichotomy of gonadal function in Prader-Willi syndrome from early 
infancy through the fourth decade. Hum Reprod. 2015;30(11):2587-96. https://doi.org/10.1093/humrep/dev213.

12. Pellikaan $K$, Rosenberg AGW, Kattentidt-Mouravieva AA, Kersseboom R, Bos-Roubos AG, Veen-Roelofs JMC, et al. Missed diagnoses and health problems in adults with Prader-Willi syndrome: recommendations for screening and treatment. J Clin Endocrinol Metab. 2020;105(12):e467187. https://doi.org/10.1210/clinem/dgaa621.

13. Corona G, Giagulli VA, Maseroli E, Vignozzi L, Aversa A, Zitzmann M, et al. Therapy of endocrine disease: testosterone supplementation and body composition: results from a meta-analysis study. Eur J Endocrinol. 2016;174(3):R99-116. https://doi.org/10.1530/EJE-15-0262.

14. Fisher $\mathrm{BG}$, Acerini $\mathrm{CL}$. Understanding the growth hormone therapy adherence paradigm: a systematic review. Horm Res Paediatr. 2013;79(4):18996. https://doi.org/10.1159/000350251.

15. Hirsch HJ, Benarroch F, Genstil L, Pollak Y, Derei D, Forer D, et al. Long-term weight control in adults with Prader-Willi syndrome living in residential hostels. Am J Med Genet A. 2021. https://doi.org/10.1002/ajmg.a.62101.

16. Laron Z. The GH-IGF1 axis and longevity. The paradigm of IGF1 deficiency. Hormones (Athens). 2008;7(1):24-7. https://doi.org/10.14310/horm.2002. 1111034.

17. Boguszewski CL, Boguszewski MCDS. Growth hormone's links to cancer. Endocr Rev. 2019;40(2):558-74. https://doi.org/10.1210/er.2018-00166.

18. Murphy N, Carreras-Torres R, Song M, Chan AT, Martin RM, Papadimitriou $\mathrm{N}$, et al. Circulating levels of insulin-like growth factor 1 and insulin-like growth factor binding protein 3 associate with risk of colorectal cancer based on serologic and mendelian randomization analyses. Gastroenterology. 2020;158(5):1300-1312.e20. https://doi.org/10.1053/j.gastro.2019. 12.020.

19. Renehan AG, Zwahlen M, Minder C, O'D wyer ST, Shalet SM, Egger M. Insulin-like growth factor (IGF)-I, IGF binding protein-3, and cancer risk: systematic review and meta-regression analysis. Lancet. 2004;363(9418):1346-53. https://doi.org/10.1016/S0140-6736(04) 16044-3.

20. Deal CL, Tony M, Höybye C, Allen DB, Tauber M, Christiansen JS. Growth Hormone in Prader-Willi Syndrome Clinical Care Guidelines Workshop Participants Growth Hormone Research Society workshop summary: consensus guidelines for recombinant human growth hormone therapy in Prader-Willi syndrome. J Clin Endocrinol Metab. 2011;98(6):1072-87.

21. Frixou M, Vlek D, Lucas-Herald AK, Keir L, Kyriakou A, Shaikh MG. The use of growth hormone therapy in adults with Prader-Willi syndrome: a systematic review. Clin Endocrinol (Oxf). 2021;94(4):645-55. https://doi. org/10.1111/cen.14372.

22. Hirsch H, Gross-Tsur V. Growth hormone treatment for adults with PraderWilli syndrome: another point of view. Orphanet J Rare Dis. 2021

23. Höybye C, Holland AJ, Driscoll DJ. Clinical and Scientific Advisory Board of The International Prader-Willi Syndrome Organisation Time for a general approval of growth hormone treatment in adults with Prader-Willi syndrome. Orphanet J Rare Dis. 2021;16(1):69.
24. Tauber M, Hoybye C. Endocrine disorders in Prader-Willi syndrome: a model to understand and treat hypothalamic dysfunction. Lancet Diabetes Endocrinol. 2021

25. Deal C, Tony M, Höybye C, Allen DB, Tauber M, Christiansen JS and the 2011 GH in PWS Clinical Care Guidelines Workshop Participants. Growth Hormone Research Society Workshop Summary: Consensus Guidelines for Recombinant Human Growth Hormone Therapy in Prader-Willi Syndrome. J Clin Endocrinol Metab. 2013; 98, E1072-87

26. Frixou M, Vlek D, Lucas-Herald AK, Keir L, Kyriakou A, Shaikh MG. The use of growth hormone therapy in adults with Prader-Willi syndrome: a systematic review. Clin Endocrinol (Oxf). 2020. https://doi.org/10.1111/ cen.14372.

27. Götherström G, Elbornsson M, Stibrant-Sunnerhagen K, Bengtsson BÅ, Johannsson G, Svensson J. Ten years of growth hormone $(\mathrm{GH})$ replacement normalizes muscle strength in GH-deficient adults. J Clin Endocrinol Metab. 2009;94(3):809-16. https://doi.org/10.1210/jc.2008-1538.

28. Sode-Carlsen R, Farholt S, Rabben KF, Bollerslev J, Schreiner T, Jurik AG, Christiansen JS, Höybye C. One year of growth hormone treatment in adults with Prader-Willi syndrome improves body composition: results from a randomised, placebo controlled study. J Clin Endocrinol Metab. 2010;95:4943-50

29. Shukur HH, Hussain-Alkhateeb L, Farholt S, Nørregaard O, Jørgensen AP, Hoybye C. Effects of Growth Hormone treatment on sleep-related parameters in adults with Prader-Willi syndrome, J Clin Endocrinol Metab. 2021; dgab300. https://doi.org/10.1210/clinem/dgab300

30. Fintini D, Grugni G, Bocchini S, Brufani C, Di Candia S, Corrias A, Delvecchio M, Salvatoni A, Ragusa L, Greggio N, Franzese A, Scarano E, Trifirò G, Mazzanti L, Chiumello G, Cappa M, Crinò A; Genetic Obesity Study Group of the Italian Society of Pediatric Endocrinology and Diabetology (ISPED). Disorders of glucose metabolism in Prader-Willi syndrome: Results of a multicenter Italian cohort study. Nutr Metab Cardiovasc Dis. 2016;26(9):842-7. https://doi.org/10.1016/j.numecd.2016.05.010

31. Höybye C, Beck-Peccoz P, Simsek S, Zabransky M, Zouater H, Stalla G, Murray RD. Safety of current recombinant human growth hormone treatments for adults with growth hormone deficiency and unmet needs. Expert Opin Drug Saf. 2020;19(12):1539-48. https://doi.org/10.1080/ 14740338.2020.1839410.

32. Kido Y, Sakazume S, Abe Y, Oto Y, Itabashi H, Shiraishi M, Yoshino A, Tanaka Y, Obata K, Murakami N, et al. Testosterone replacement therapy to improve secondary sexual characteristics and body composition without adverse behavioral problems in adult male patients with Prader-Willi Syndrome: an observational study. Am J Med Genet A. 2013;161A:2167-73. https://doi.org/10.1002/ajmg.a.36048.

\section{Publisher's Note}

Springer Nature remains neutral with regard to jurisdictional claims in published maps and institutional affiliations.
Ready to submit your research? Choose BMC and benefit from:

- fast, convenient online submission

- thorough peer review by experienced researchers in your field

- rapid publication on acceptance

- support for research data, including large and complex data types

- gold Open Access which fosters wider collaboration and increased citations

- maximum visibility for your research: over $100 \mathrm{M}$ website views per year

At BMC, research is always in progress.

Learn more biomedcentral.com/submissions 